\title{
Hallazgo de la traducción perdida del Orlando furioso (1604) de Conzalo de Oliva, ms 000.029 de la Biblioteca de la Universidad de Navarra, y comparación con las otras traducciones contemporáneas*
}

Discovery of the Lost Translation of the Orlando furioso (1604) by Gonzalo de Oliva, ms 000.029 of the Library of the University of Navarra, and its Comparison with the other Contemporary Translations

Martín Zulaica López

Departamento de Filología

Universidad de Navarra

31009 Pamplona

mzulaica.4@alumni.unav.es

Orcid ID: 0000-0002-7911-4822

Resumen: El presente artículo tiene por objeto dar a conocer el hallazgo de un manuscrito perdido que contiene una traducción áurea del Orlando furioso. A la vista del panorama de circulación del poema de Ariosto en español durante el Siglo de Oro, ofreceremos una descripción codicológica del manuscrito, señalaremos la procedencia de los diversos paratextos que lo integran, lo compararemos con las otras traducciones áureas del texto -centrándonos en la de Jiménez de Urrea-, incidiremos en la tarea de reescritura llevada a cabo sobre él, y, por último, enjuiciaremos el valor que esta traducción tiene tanto para los estudiosos del Siglo de Oro como para cualquier lector.

Palabras clave: Gonzalo de Oliva. Ariosto. Orlando furioso. Traducción. Poesía. Siglo de Oro.

\footnotetext{
* El presente trabajo se enmarca dentro del Proyecto I+D+i del Ministerio de Economía y Competitividad FFI2015-64050: Magia, épica e historiografía hispánicas: relaciones literarias y nomológicas. Quiero agradecer al personal de la Biblioteca de la Universidad de Navarra las facilidades que me han dado para poder estudiar el manuscrito de Gonzalo de Oliva, y a Rafael Zafra y Victoriano Sainz su ayuda inestimable.
} 
Abstract: The purpose of this article is to announce the finding of a lost manuscript that contains a 17th century Spanish translation of the Orlando furioso. Considering the circulation of Ariosto's poem in Spain during this period, we offer a codicological description of the manuscript, we indicate the origin of the various paratexts that make it up, we compare it with the other golden translations of the text -focusing on the one of Jiménez de Urrea-, we focus on the task of rewriting carried out on it, and, finally, we judge the value that this translation has for both the Golden Age scholars and for any reader.

Keywords: Gonzalo de Oliva. Ariosto. Orlando furioso. Translation. Poetry. Spanish Golden Age.

E 1 presente artículo tiene por objeto dar a conocer el hallazgo de un manuscrito hasta ahora perdido, que contiene la traducción áurea del $O r$ lando furioso de Gonzalo de Oliva (1604), y ofrecer un primer acercamiento crítico. Quizá algún estudioso de Cervantes recuerde la nota en que Diego Clemencín daba noticia de la existencia de este manuscrito, pero lo más probable es que haya caído en el olvido. Por tanto, encuentro que la manera más oportuna de introducir dicha nota es tratar en primer lugar la cuestión que anotaba el académico y traer a colación el manuscrito en el mismo momento en que él lo hizo, con la diferencia de que en esta ocasión podremos, después, detenernos a estudiarlo. Clemencín anotó ampliamente en el volumen primero a su edición del Quijote (1833) el pasaje del escrutinio de la biblioteca del hidalgo. Refiriéndose a los reproches del cura y viendo en ellos la opinión del propio Cervantes, afirma que hizo una crítica benigna de la traducción del Orlando furioso del capitán Jerónimo Jiménez de Urrea porque al justificar su condena a la hoguera solo le alza los reproches habituales a las traducciones de libros de versos, cuando podrían haberse criticado en ella muchos otros defectos. ${ }^{1}$ Comenta, además, algunos pasajes omitidos o modificados por el capitán y añade dos testimonios de crítica contemporáneos a su traducción. El primero de ellos, la Respuesta del Capitán Salazar al Bachiller de Arcadia, atribuido a Diego Hurtado de Mendoza, ${ }^{2}$ donde leemos lo siguiente:

Y don Jerónimo de Urrea, ¿no ha ganado fama de noble escritor y, aun según dicen, muchos dineros (que importa más) por haber traducido a

1. "La censura, que aquí hace Cervantes de esta traducción, es todavía sobradamente benigna, puesto que atribuye sus defectos a las causas generales que dificultan las traducciones de obras cuyos originales están en verso, sin mencionar otros innumerables de mala inteligencia, mala versificación y mal lenguage de que adolece la del Orlando. Y fuera de esto, omitió u añadió Urrea en el original lo que quiso según su antojo" (Clemencín 120).

2. Sobre esta atribución, ver Varo Zafra. Para una edición reciente de las cartas, López del Castillo 151-72. 
Orlando el furioso, y donde el autor decía cavalieri, decía él caballeros, y donde el otro decía arme decía él armas, y donde amori amores [?]; pues desta manera yo me haría más libros que Matusalém. (López del Castillo 167)

\section{El fingido capitán Salazar recrimina a Jiménez de Urrea en la carta los muchos dineros que presuntamente le hizo ganar su traducción del Furioso, ${ }^{3}$ reeditada hasta en 12 ocasiones en el siglo XVI. ${ }^{4} \mathrm{Y}$ amonesta también la traducción entre lenguas vulgares rebajando su valor. El pasaje es homologable al del Quijote en que el caballero conoce a un avariento traductor del italiano dando cuenta del desprestigio existente entre los círculos humanistas tanto por quienes acudían a estas traducciones de obras escritas en otras lenguas vulgares como por quienes}

3. La cuestión de los hoy llamados "derechos de autor" en el Siglo de Oro no ha sido todavía estudiada de forma sistemática. La última y más completa aproximación es la de Díez Borque. El beneficio que los autores obtenían por estampar sus obras es difícil de determinar y dependía directamente del acuerdo establecido con el impresor (mediante contrato puntual o cesión del privilegio de impresión). En el caso de Jiménez de Urrea solamente encontramos señal de los privilegios de impresión sobre su traducción en las ediciones antuerpienses de 1554 y 1558 . El texto, que no reproduce ningún documento concreto, pues Jiménez de Urrea obtuvo varios para diferentes lugares, dice así: "Concede su majestad a don Ieronimo de Urrea, que por tiempo de diez años ninguno pueda imprimir ni vender en los reynos de Castilla, y de Aragon, y en los otros sus reynos y señorios, la version que el ha hecho de Orlando furioso sin su commission, so las penas contenidas en los originales previlegios. Yo el Rey. // Lo mismo concede el serenissimo Rey de Portugal, y assi mismo el Sumo Pontifice, Señoria de Venecia, Duque de Florencia y Duque de Ferrara". Fijándonos en las fechas y las localizaciones de las diferentes ediciones, solamente podemos asegurar que obtuvo beneficios de estas dos, aunque lo más razonable, teniendo en cuenta el celo con que solicitó los privilegios es que los recibiese de todas las ediciones de su traducción que vieron la luz mientras vivía. Entre las ediciones posteriores a su muerte, solamente en la de 1578 encontramos información sobre esta cuestión, pues se reproduce una licencia que concedió Felipe II para imprimir la traducción ante la petición del librero Gaspar de Ortega: "Damos licencia y facultad a qualquier impressor de estos nuestros reynos, para que por esta vez pueda imprimir el dicho libro [...] sin que por ello cayga ni incurra en pena alguna".

4. Son las siguientes: Amberes (la princeps en 1549 y otras dos en 1554 y 1558), Lyon (1550 y 1556), Venecia (1553 y 1575), Barcelona (1564), Medina del Campo (1572), Salamanca (1578), Toledo y Bilbao (ambas en 1583). Para una información completa sobre estas ediciones, Segre/Muñiz 72-74. Sobre el número de ediciones de la traducción de Jiménez de Urrea circulan informaciones dispares en los repertorios bibliográficos de Simón Díaz, que menciona 15, y de Wilkinson, que menciona 16; los trabajos de Pierce -que eleva el número a 18 partiendo de Agnelli/ Ravegnani-, Geneste -que menciona 15 (diferentes de las de Simón Díaz)- y Vaganay -que menciona 14-; y finalmente Chevalier, la edición de Segre/Muñiz y Cacho Blecua en Jauralde Pou, que mencionan las mismas 12 ediciones y que parecen estar en lo cierto. La noticia de las restantes ediciones no coincidentes con las que recogen estos últimos puede explicarse por diversos motivos con la excepción de una edición toledana de 1588, solamente mencionada por Wilkinson, de la que solo se conservaría un ejemplar en una colección privada que no se detalla. Aún no disponemos de un estudio bibliográfico detallado en que se identifiquen todos los ejemplares y se precise, al menos, su edición y posible emisión. 
las realizaban. ${ }^{5}$ Un tipo "de traducción, no impulsado por motivos estéticos, creativos o de combate humanístico, sino también, o sobre todo, por la oportunidad editorial y comercial" (Micó 2002, 88). ${ }^{6}$ La segunda crítica que menciona Clemencín es la famosa composición $A$ un buen caballero, y mal poeta, la lira de Garcilaso contrahecha de Hernando de Acuña, reescritura paródica de la Ode ad florem Gnidi de Garcilaso,' quien reprende a Jiménez de Urrea por cuanto ha escrito y le invita a dedicarse exclusivamente a las armas (Acuña 322-25):

Por vuestra cruda mano aquella triste traducción furiosa no tiene hueso sano, $\mathrm{y}$ vive sospechosa que aún vida le daréis más trabajosa.

Mas digo finalmente, aunque decirlo es ya cosa excusada que no hagáis la gente de vos maravillada, juntando mal la pluma con la espada.
Mueran luego a la hora las públicas estancias y secretas, y no queráis ahora que vuestras imperfetas obras y rudo estilo a los poetas den inmortal materia para cantar, en verso lamentable, las faltas y miseria de estilo tan culpable, digno que no sin risa de él se hable.

(vv. 41-45, 96-110)

Acuña tenía motivos para manifestar cierta inquina por la "triste traducción furiosa" de Jiménez de Urrea, pues los dos rivalizaron con sus traducciones de Le Chevalier délibéré de Olivier de la Marche que vieron la luz en Amberes respectivamente en 1553 y 1555 , y, además, el aragonés tuvo a la vista la traduc-

5. “-¡Cuerpo de tal -dijo don Quijote-, y qué adelante está vuesa merced en el toscano idioma! Yo apostaré una buena apuesta que adonde diga en el toscano piache, dice vuesa merced en el castellano «place», y adonde diga più dice «más», y el su declara con «arriba» y el giù con «abajo». -Sí declaro, por cierto -dijo el autor-, porque esas son sus propias correspondencias. -Osaré yo jurar -dijo don Quijote- que no es vuesa merced conocido en el mundo, enemigo siempre de premiar los floridos ingenios ni los loables trabajos. ¡Qué de habilidades hay perdidas por ahí! ¡Qué de ingenios arrinconados! ¡Qué de virtudes menospreciadas! Pero, con todo esto, me parece que el traducir de una lengua en otra, como no sea de las reinas de las lenguas, griega y latina, [...] el traducir de lenguas fáciles ni arguye ingenio ni elocución, como no le arguye el que traslada ni el que copia un papel de otro papel" (Quijote II 62, 1249). Cervantes está parodiando además el procedimiento de traducción "palabra por palabra", con una actitud humanística de raigambre ciceroniana (De finibus III 15).

6. Sobre la traducción en la época ver los trabajos de Micó (2002; 2006). Sobre las traducciones entre español e italiano en ambas direcciones Muñiz Muñiz (2010, 35-36).

7. Romera Castillo estudia detenidamente la construcción del poema de Acuña a partir del modelo de Garcilaso. 
ción de Acuña y la empleó asiduamente para preparar la suya. ${ }^{8}$ Los trabajos de traducción de Jiménez de Urrea distaban de gozar de una aceptación unánime y, respecto de la que hizo del Furioso, podrían exponerse tantos comentarios críticos como favorables. ${ }^{9}$

A continuación, Clemencín menciona las otras dos traducciones del poema de Ariosto que, junto a la de Jiménez de Urrea, vieron la luz en letras de molde en el siglo XVI, si bien tuvieron una difusión mucho menor: la de Hernando Alcocer (Toledo: Juan Ferrer, 1550) y la de Diego Vázquez de Contreras (Madrid: Francisco Sánchez, 1585). ${ }^{10}$ Por último, añade:

$\mathrm{Ni}$ en D. Nicolás Antonio ni en otro escritor alguno encuentro noticia de la traducción del Orlando furioso, hecha en octava rima por Gonzalo de Oliva, cuyo original he visto escrito en folio de mano de[1] mismo Oliva, con sus enmiendas interlineales, y firmado en Lucena a 2 de agosto del año 1604. Oliva evitó los numerosos defectos de Urrea: tradujo fielmente; su versificación es fácil y armoniosa, y su libro, a pesar de algunos pequeños lunares, harto más digno de ver la luz pública que los de otros muchos traductores de su tiempo. (Clemencín 120-22)

Al parecer, Clemencín habría visto esta otra traducción del poema de Ariosto, pero tras esta mención nada se volvió a saber de dicho manuscrito. De la noticia se hicieron eco en la primera mitad del siglo xx Menéndez Pelayo y Portnoy, y recientemente lo han hecho Muñiz y Pintacuda, pero sin añadir nada a lo señalado por el erudito murciano. ${ }^{11}$ La traducción, como señalara Portnoy,

8. Según Clavería: "Lo que Urrea hizo no fue sino parafrasear a su manera la traducción anterior de Hernando de Acuña" (152); afirmación que precisó Geneste (161-229), pues si bien Urrea empleó el trabajo de su predecesor, no se limitó a reversificar en tercetos las quintillas de Acuña, sino que fue en muchos pasajes más fiel al texto original de La Marche -pueden verse ejemplos de ello en Geneste (184-85)-. Ahora bien, a partir de un determinado momento Urrea parece dejar de acudir al original y versifica íntegramente en base al texto de Acuña: "Nous n'en avons d'ailleurs trouvé trace, au fil du texte, que jusqu'à la strophe 260 (sur les 338 que comporte le poème de La Marche), comme si, à partir de là, Urrea s'était abandonné à la méthode la plus facile et s'était alors uniquement laissé porter par Acuña" (Geneste 186).

9. Sobre las numerosas críticas (Hurtado de Mendoza, Acuña, Ramírez Pagán, Suárez de Figueroa, Cervantes), y también comentarios favorables (Alonso de Ulloa, Hernández de Velasco, Hernando de Hoces, Zapata, Mal Lara) a las traducciones de Jiménez de Urrea, ver Geneste (222-25) y Chevalier (75-77).

10. Sobre la traducción de Vázquez de Contreras, ver Chevalier (99-105) y Pintacuda. Sobre el uso de la traducción de Alcocer por el escritor de El Crotalón, ver Vian Herrero y Chevalier (87-90).

11. "El Orlando furioso tuvo tres traductores, a cuál más infelices, Hernando de Alcocer, el capitán Jerónimo de Urrea y Diego Vázquez de Contreras, sin contar a Gonzalo de Oliva, cuyo trabajo, muy superior al parecer, quedó inédito. [...] Le menciona Clemencín en sus notas al 
es a día de hoy un fantasma bibliográfico que apenas se cita. Así, uno de los mayores expertos sobre la traducción e influencia del Orlando furioso en nuestra literatura no la menciona en un breve trabajo que, precisamente, trata sobre las traducciones antiguas de esta obra: "No se conocen traducciones de los siglos XVII y XVIII" (Micó 2010), ${ }^{12}$ ni tampoco la igualmente experta Muñiz en la voz “Ariosto, Ludovico" del Diccionario bistórico de la traducción en España (2009).

Más de cuatrocientos años después de su redacción y tras haber pasado casi completamente desapercibida, esta traducción ha sido localizada en los fondos de la Biblioteca de la Universidad de Navarra, a la que llegó mediante una donación particular en 2009. El manuscrito había pasado a manos del donante por las del sacerdote D. Santiago Guinea Iturrate, familiar y secretario particular del cardenal Segura entre 1943 y 1957, y procedía, a su vez, de la biblioteca de un descendiente de Antonio de Nebrija, el diplomático, político y escritor José del Castillo y Ayensa (1795-1861). ${ }^{13}$ La descripción bibliográfica analítica del manuscrito es la siguiente: ${ }^{14}$

\section{Pamplona, Biblioteca de la Universidad de Navarra, ms. 000.029. Gonçalo de Oliva, Orlando furioso ... traduzido en el mismo verso en lengua castellana}

\section{Orlando furiofo compuesto en otava rima por Lodovico Ariösto en lengua ita- | liäna, i della traduzido en el mismo verso en lengua castellana |}

Íncipit: "Reynaldos, Ferragut y Sacripante impedidos de poder gozar de Angélica muestran..." (f. 1r), Éxplicit: "Todo lo dicho en este i libro va su-

Quijote" (Menéndez Pelayo 225-26); "el traslado poético de Oliva por causas ignoradas no llegó a publicarse y hoy apenas lo citan los críticos" (Portnoy 218); "Nada sabemos, aparte la noticia dada por Clemencín [...] acerca de la traducción del Furioso que Gonzalo de Oliva habría realizado en 1604. El estudioso afirma allí haber visto el manuscrito" (Segre/Muñiz 47, n. 55); "[resta] Gonzalo de Oliva, cuya versión -que no consta que circulara en letras de molde- lamentablemente se considera hoy perdida" (Pintacuda 218).

12. Este trabajo es un extracto de otro mayor (Micó 2006, 11), el cual a su vez reelabora en buena parte otro anterior (Micó 2002).

13. Castillo y Ayensa era académico de número de la Real Academia Española -sillón E- desde 1833 (anteriormente fue elegido académico honorario, en 1830, y supernumerario, en 1831). Según Romero Blanco (22) -la única investigadora que se ha ocupado de la biografía de Castillo y Ayensa-, su expediente en la RAE apenas conserva documentación; pero el tomo XXI de los Libros de Actas de la Academia sí permite contemplar su labor en la institución. Entre su obra literaria destaca la publicación conjunta de sus traducciones de obras de Anacreonte, Safo y Tirteo, que vio la luz en 1832. Además, sabemos que comenzó una traducción del Orlando furioso que alcanzó al menos el primer canto, pues se refiere a ella Alberto Lista en dos cartas a Félix José Reinoso editadas por Juretschke (cartas XLVIII y LX).

14. Sigo el modelo propuesto por Montaner Frutos (100-125). 
geto a la correcion, i emienda de nuestra san I ta madre la Iglesia Católica Romana, i a la censura de la Santa Iquisicion, a I las quales me sugeto en esto i en todo. i assi lo firmé en Lucena a. 2. diäs del I mes de Agosto del año de 1604. I [firma y rúbrica:] Gonçalo de Oliva” (fig. 1), Registro: "Registro. A. B. C. D. E. F. G. H. I. K. L. M. N. O. P. Q. R. S. T. V. X. Y. Z. I Aa. Bb. Cc. Dd. Ee. Ff. Gg. Hh. Ii. Kk. Ll. Mm. Nn. Oo. Pp. Qq. I Rr. numero 40. todos son quadernos, sino Rr. q̃ es quinterno" (f. 322r), seguido por la "Tabla A A. Agramãte" (comienza en el vuelto del último folio del poema y abarca 6 folios más).

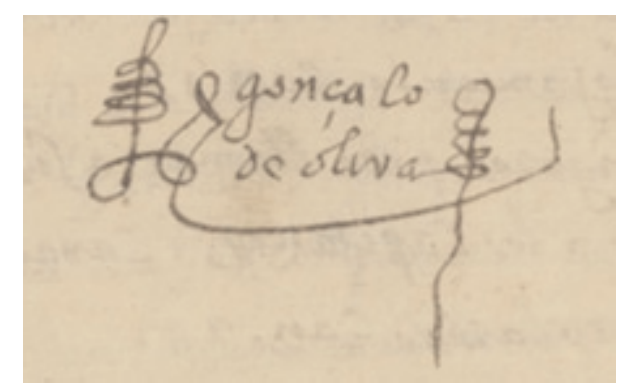

Figura 1. Firma y rúbrica de "Gonçalo de Oliva" (f. 322r)

Folio $(304 \times 205 \mathrm{~mm})$; 39 cuaterniones, 1 quinión, 1 senión; II $+322 \mathrm{ff}$. $+[6]$ h. + II $=332 \mathrm{f}$.

Papel verjurado; filigranas: a lo largo del manuscrito figuran catorce filigranas diferentes: en ambas guardas, corazón con una cruz inscrita, con la letra P encima y las letras G D debajo (fig. 2); en los cuadernos A, B, C, D, P, Q, R, S, T, V, Z, además del pliego I1/I8, ángel orante inscrito en un círculo, con un trébol de hojas orbiculares encima y un rombo debajo (fig. 3); en los cuadernos E, F, X, Y, Aa, Bb, Cc, Dc, Ee, Ff, además de los pliegos G2/G7, Gg1/Gg8 y el folio reemplazado H2, ángel orante inscrito en un círculo, con un trébol de hojas romboides encima y una letra B debajo (fig. 4); en los cuadernos G, H, I, K, L, M, N, O, corazón con cruz inscrita y con las letras M A en la parte inferior (fig. 5); en los cuadernos Ii, Kk, Ll, Mm, corazón con cruz inscrita, con una cruz situada debajo y las letras A A franqueándola (fig. 6); en los cuadernos Nn, Oo, Pp, Qq, Rr, Ss, corazón con cruz inscrita con las letras B B debajo (fig. 7); dentro de los cuadernos encontramos las siguientes excepciones: en el pliego 03/O4, corazón con cruz inscrita, con la letra C encima y las letras L A debajo 
(fig. 8); en el pliego Gg2/Gg7, corazón con cruz inscrita, letra A en la base de la cruz y, fuera del corazón, letras B F debajo (fig. 9); en los pliegos Gg3/Gg6 y Gg4/Gg5, corazón con cruz inscrita, letra B en la base de la cruz y, fuera del corazón, letras B A debajo (fig. 10); en los pliegos Hh1/Hh8 y Hh2/Hh7, corazón con cruz inscrita y las letras I P debajo (fig. 11); en los pliegos Hh3/Hh6 y Hh4/Hh5, corazón con cruz inscrita y las letras P в debajo (fig. 12); además encontramos otras en folios reemplazados: en A5, corazón con cruz inscrita y una letra B debajo (fig. 13); en H8, corazón con cruz inscrita con la letra B en la base de la cruz, y, fuera del corazón, la letra B debajo (fig. 14); en K7, corazón con una cruz inscrita, con las letras G G situadas debajo (fig. 15); por último, también han sido reemplazados E3 y P2 por ff. sin filigranas. Foliación en arábigos de la misma tinta y mano que el texto, en el ángulo superior derecho del recto, que no incluye el último senión, en el cual figura la Tabla final. Texto a doble columna sin pautado, que incluye ocho octavas por página. Titulillos centrados en todas las páginas indicando el canto al que pertenecen. Letra humanística cursiva corriente del XVII en tinta negra, tanto en el cuerpo del texto como en los títulos y titulillos. Sin ilustraciones.

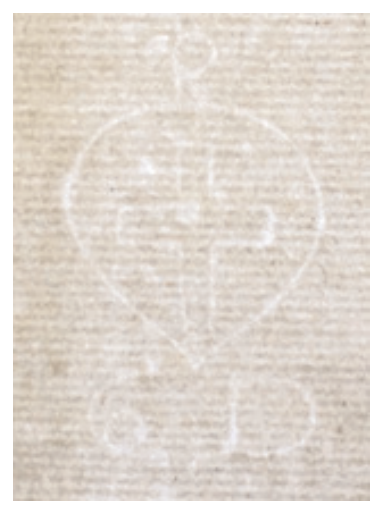

Figura 2

\section{CATÁLOGO DE FILIGRANAS}

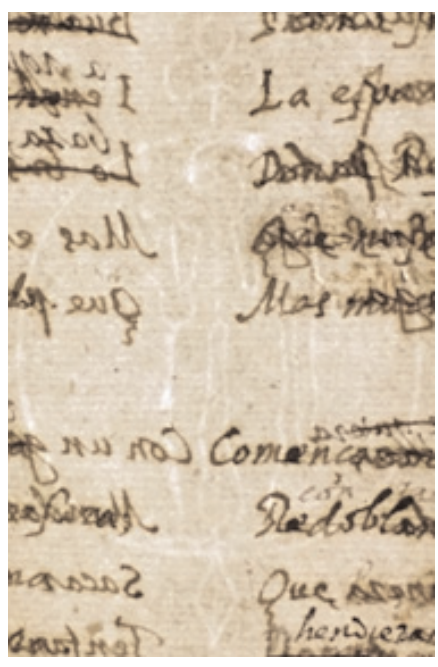

Figura 3

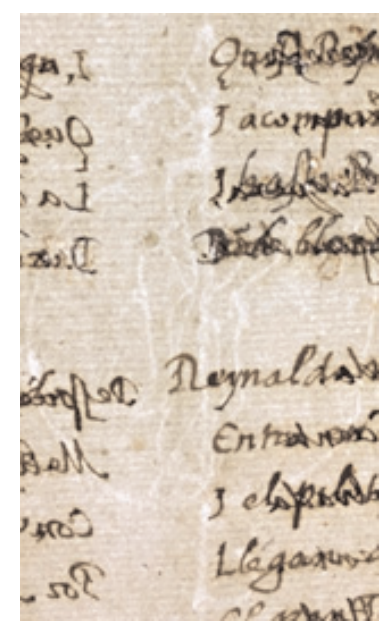

Figura 4 


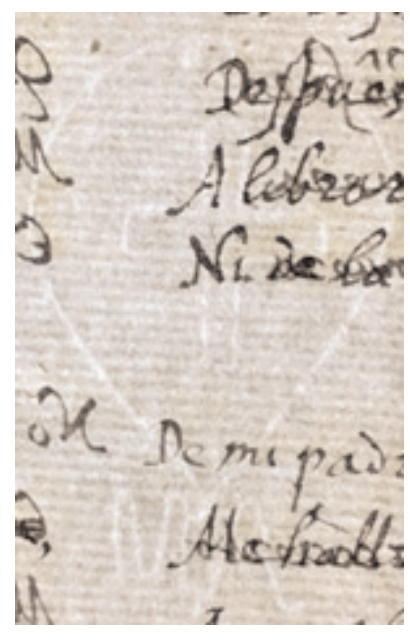

Figura 5

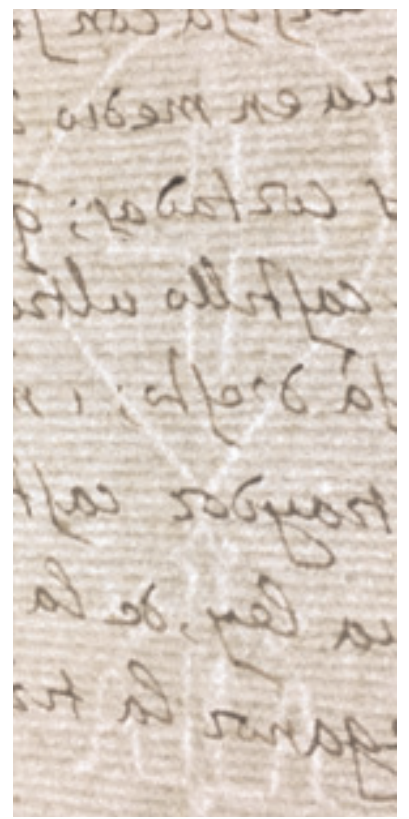

Figura 6

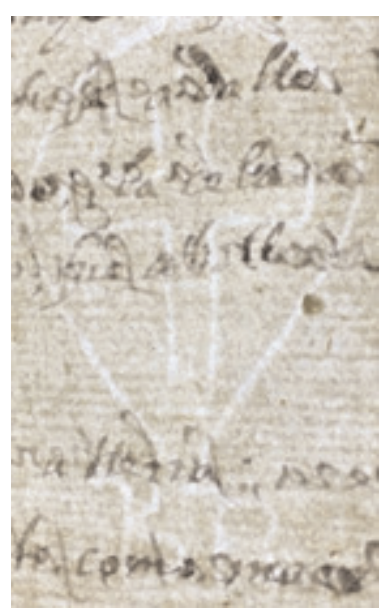

Figura 7

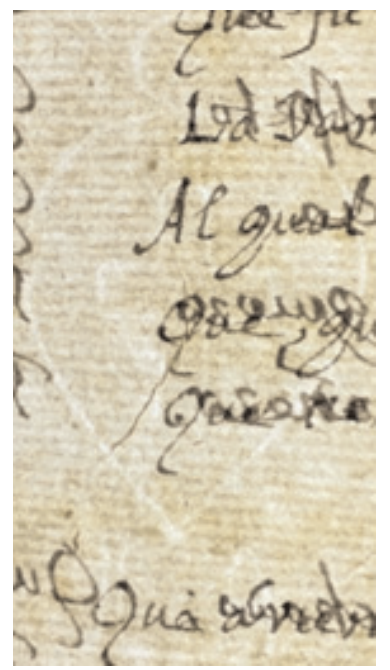

Figura 8

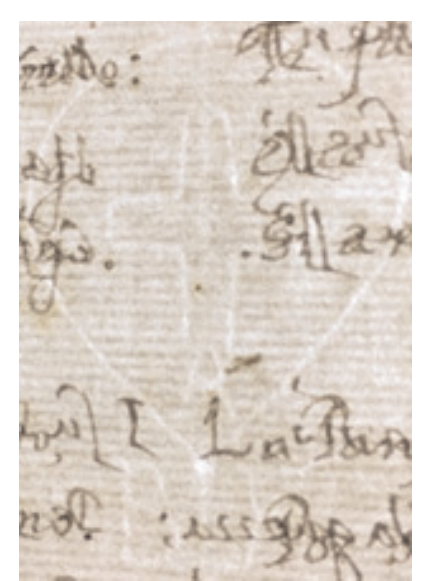

Figura 9

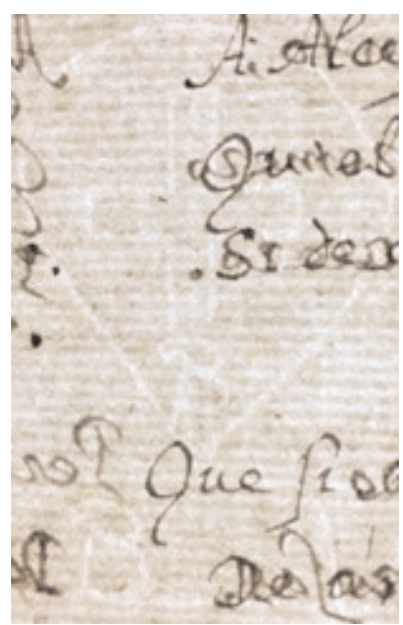

Figura 10 


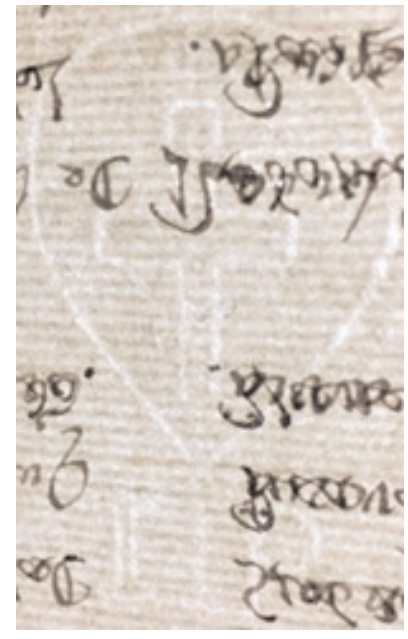

Figura 11

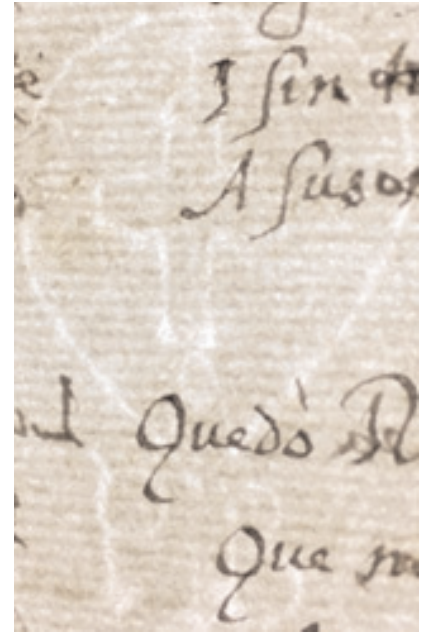

Figura 12

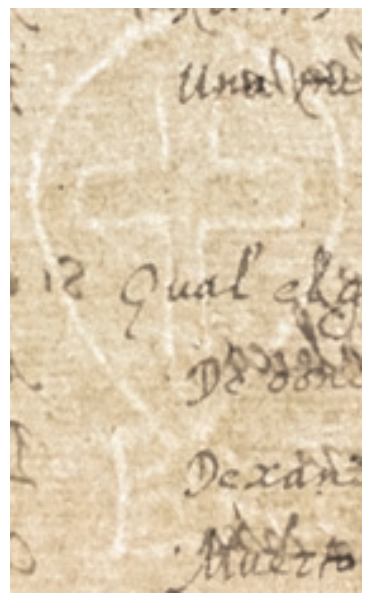

Figura 13

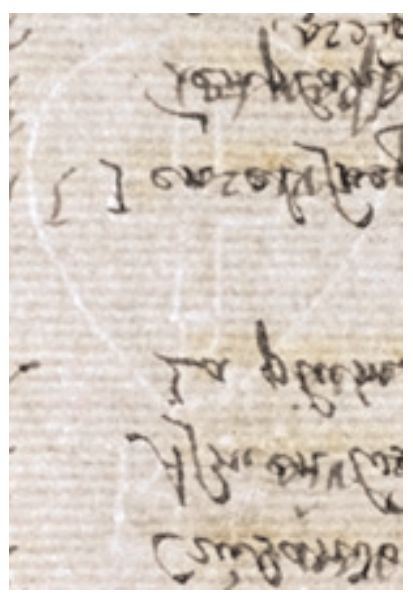

Figura 14

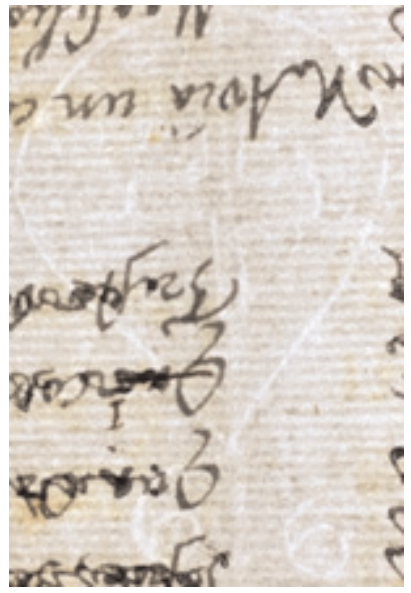

Figura 15

Encuadernación de época, $309 \times 214 \times 45 \mathrm{~mm}$, en pergamino; lomo con cuatro nervios y cabezadas, con la inscripción en tinta: "Orlando I furioso". Presenta dos hojas de guarda iniciales y otras dos finales, en ambos casos una fija y otra volante.

En el folio 322r el manuscrito incluye un Registro en que se da relación de las signaturas de los treinta y nueve cuaterniones y del quinión que lo forman hasta dicho folio; por tanto, no incluye el último senión (fig. 16). 


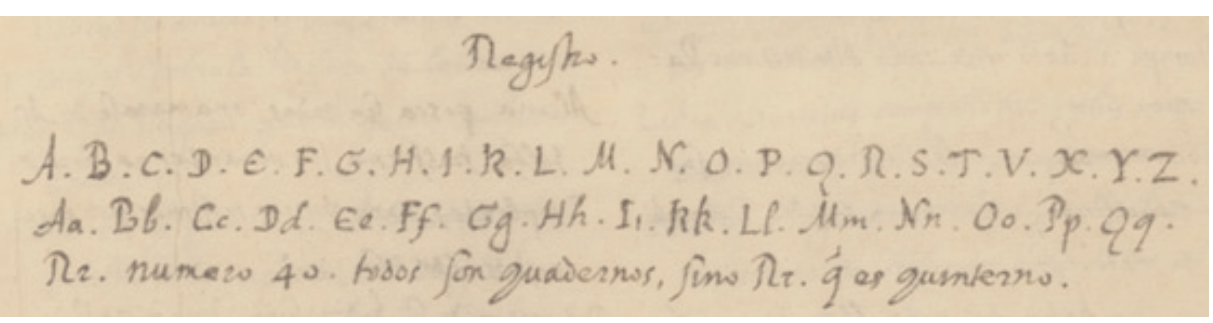

Figura 16. Registro (f. 322r)

Cada canto incorpora una octava argumental que anticipa su contenido y una alegoría que interpreta su moralidad, las cuales son traducción de textos de Ludovico Dolce y de Thomasso Porcacchi respectivamente. Estos textos aparecieron acompañando de forma conjunta al poema de Ariosto en numerosas ocasiones hasta 1604. Las octavas argumentales, alegorías, aclaraciones, declaraciones, anotaciones, tablas, etc., que prepararon diferentes humanistas para acompañar al texto de Ariosto a lo largo de los siglos XVI y XVII -concediéndole dignidad de clásico- son muy numerosas, y además registran variantes, pues sus autores iban mejorándolas en sucesivas ediciones. Si bien la primera edición que incluye los textos mencionados de Dolce y Porcacchi es la impresa en Venecia en casa de los hermanos Guerra en 1568, la versión del texto de las alegorías que se incluye en ella no se corresponde exactamente con la que tradujo el lucentino. Además, como hemos señalado en la descripción bibliográfica, el manuscrito de Oliva incorpora la traducción de una Tabla final que encontramos por vez primera en compañía de los textos de Dolce y de Porcacchi en la edición de 1577 de Girolamo Polo. De este modo, teniendo en cuenta todos los elementos que el manuscrito incluye y tras acudir por una parte a los Annali delle edizioni ariostee (1933) y también -con el objetivo de completar la información que este no recoge- al EDIT16 (Censamiento nazionale delle edizioni italiane del XV secolo), he identificado un conjunto final de doce ediciones a partir de las cuales pudo haber trabajado Oliva. Se trata de las de: Girolamo Polo de 1577 (CNCE 2788), 1583 (CNCE 2803), 1586 (CNCE 2812) y 1589 (CNCE 2828); Rampazetto de 1587 (CNCE 2818); Bordogna de 1587 (CNCE 2819); Alberti de 1589 en $8^{\circ}$ (CNCE 2827); Bindoni de 1589 (CNCE 2826); Prati de 1595 (CNCE 60881) y de 1603 (no recogida en el CNCE, pero sí por Agnelli y Ravegnani, se conserva un ejemplar en la BNFrancia); Misserino de 1596 en $8^{\circ}$ (CNCE 2836) e Imberti de 1600 (CNCE 2841). ${ }^{15}$

15. La mayoría de estos editores (Polo, Rampazzetto, Alberti, Misserino e Imberti) prepararon más ediciones del poema de Ariosto, pero solamente las aquí recogidas reúnen exactamente los materiales que Oliva tradujo. 
Junto con el volumen, se conservan además dos hojas sueltas que contienen copias de varios documentos procedentes de los libros de sacramentos de la Iglesia mayor parroquial de san Mateo de Lucena, que podemos datar en la primera mitad del siglo XVIII, ${ }^{16}$ a partir de los que se obtienen las siguientes informaciones:

- bautismo de Gonzalo de Oliva a 9 de febrero de 1556;

- matrimonio de Gonzalo de Oliva con María del Valle celebrado el 15 de abril de 1596;

- noticia del testamento de Gonzalo de Oliva fechado en Lucena a 24 de noviembre de 1600 ;

- dos partidas de bautismo fechadas en 1612 en que firma como testigo la viuda del escritor.

De estas copias de documentos se desprende un sucinto perfil biográfico sobre el autor de la enigmática traducción mencionada por Clemencín. Por lo que a nosotros interesa, Gonzalo de Oliva, apenas menor en edad a otro lucentino ilustre, el también poeta Luis Barahona de Soto (1548-1595), contaba 48 años cuando firmó el manuscrito de su traducción íntegra del Orlando furioso en 1604. Por la noticia de su testamento es bastante probable que a la edad de 44 años no tuviera hijos, pues nombra herederos a sus tres hermanos: Hernando, Bartolomé y María. Sabemos que con posterioridad a 1604 y con anterioridad a 1612, fecha esta última en que su mujer figura como viuda, lo encontró la muerte mientras estaba ocupado en la corrección de su traducción.

Podemos decir que su trabajo se distancia del de Jiménez de Urrea al menos en la primera de las dos críticas levantadas en contra de este por sus con-

16. Con el fin de conocer en qué momento se suscitó el interés por Gonzalo de Oliva que llevó a solicitar la reproducción de tales documentos, y poder perfilar algo mejor la historia del manuscrito, he procurado dos medios de datación. En primer lugar, he tratado de identificar la filigrana papelera que se conserva en una de estas copias en diversas fuentes: las historias del papel de Valls i Subirà $(1970 ; 1978)$ y de Gayoso, así como en el metabuscador del proyecto Bernstein; y con la generosa ayuda de María Dolores Díaz de Miranda también en el Corpus de Filigranas Hispánicas (aún no abierto al público). La filigrana representa un corazón tocado por la punta de una flecha y con la palabra VEIRET escrita debajo en letras mayúsculas. Con todo, por el momento no me ha sido posible localizar su procedencia y periodo de circulación. En segundo lugar, esta vez con la ayuda y consejo de Diego Navarro Bonilla, he llevado a cabo una datación paleográfica aproximada que situaría estas copias en la primera mitad del siglo XVIII por varios motivos: las erres de los documentos están ya alejadas del modelo de martillo $\mathrm{y}$ asemejan una x o un aspa, y los numerales muestran gruesos trazados de la pluma con un $d u c$ tus claro también típico del XVIII. 
temporáneos y mencionadas por Clemencín. Como no logró dar a la imprenta su obra, aunque esa fuera su intención, su ímprobo esfuerzo por preparar una nueva traducción del poema de Ariosto no pudo reportarle los pingües beneficios que se juzgaba que había obtenido el capitán por la suya. Cuestión diferente es su mérito artístico, a pesar de que Clemencín afirmase que, frente al trabajo de Jiménez de Urrea, Oliva "tradujo fielmente" o que "su versificación es fácil y armoniosa". No es posible en este espacio desarrollar un trabajo que compare ambas traducciones completas, o lo que aún es más importante, la de Oliva con el texto italiano original. ${ }^{17}$ Pero al menos, llevaremos a cabo un análisis preliminar teniendo en cuenta la labor del lucentino frente a la de sus predecesores.

Como hemos señalado más arriba, a Jiménez de Urrea se le criticaron sus intromisiones en el texto eliminando e introduciendo pasajes en el poema. Él mismo, consciente de los posibles reproches que podrían hacerse contra la fidelidad de su traducción, se había adelantado en un Aviso al lector señalando algunos de los lugares en que había omitido parte del texto: como son las octavas 1-4, 18 y 20-62 del canto tercero que le habían llevado a la refundición de los cantos segundo y tercero; las octavas 81-82 del canto decimotercero, y las octavas 58-59 y 80 del canto trigésimo tercero:

Porque muchas personas de España aficionadas ala lecion del Orlando furioso dexavan de gozar de la dulçura y primor de aquel Poema a causa de no tener tan entero conocimiento de la lengua Toscana en que esta escrito me parecio tomar trabajo de le traduzir y poner en Romance Castellano quan acertada y fielmente supe, y porque la mayor virtud de la traslacion es la fidelidad, y en esta por ventura parecera a algunos yo aver faltado comparando este libro con su Original estancia por estancia, quiero aquí declarar mi intencion. Es verdad que en el numero de los cantos ay variedad, porque los quarenta y seis que el Ariosto compuso estan reduzidos a quarenta y cinco, hecho del segundo y tercero uno, en lo qual allende que yo tuve atencion a quitar la confusion y tinieblas que la aspereza y desgusto de nombres antiguos e ignotos alli contenidos engendrava, también seguy el consejo y voto de varones prudentes y sabios que me persuadieron a tal mudança, en que interuino y fue principal el

17. Un trabajo más detenido -siguiendo la estela de los de Parducci, Van Horne, Bertini (1934, 1935 y 1961), Morreale o del llorado Mazzocchi (2009), en su estudio de la de Urrea- que compare múltiples pasajes del texto de Ariosto con la traducción de Oliva habrá de esperar. 
señor Don Francisco de Este, a quien particularmente este cuydado podia tocar, por ser toda la obra endereçada a celebrar la gloria de su tio y padres los Duques de Ferrara, especial que todo lo que alli tan obscuro y perplexo dellos se refiere, esta repetido mas abierto y claro en diversas partes del libro, assimismo del canto terciodecimo y treynta y tres me parecio remover dos o tres estancias, porque aunque son ingeniosas, no espere que en España serian tan ace[p]tas. (Ariosto 81)

A estas supresiones anunciadas hay que añadir las de las octavas 29 del canto trigésimo cuarto y 5 del cuadragésimo segundo, que Jiménez de Urrea elimina sin dar aviso. En la traducción poco posterior llevada a cabo por Hernando de Alcocer ya se criticaban estas infidelidades. La suya iba introducida por un texto al lector que es una refutación al de Jiménez de Urrea. En él afirmaba haber traducido "sin dejar estancia atrás", haciendo mención expresa a la incorporación del pasaje en alabanza a la casa de Este suprimido por Jiménez de Urrea, puesto que la "mayor virtud que puede tener la traducción es la fidelidad" (Gutiérrez Hermosa 115-23). Pero lo cierto es que, aunque incorpora completo este pasaje, suprime después otros elogios a italianos que se hacen en el poema (XXVI 50-51 y XXXVII 8-23), y en total cerca de unas sesenta octavas. ${ }^{18} \mathrm{Y}$ no quedan aquí las intromisiones de Jiménez de Urrea o de Alcocer en el texto, pues junto a las supresiones también encontramos diversas adiciones encomiásticas a personajes españoles. El primero de ellos lo advierte en el ya mencionado Aviso:

Solo pido a los Letores que me perdonen, si por afficion de mi patria he usurpado demasiada licencia, en lugares vazios y ociosos entremetiendo la memoria de algunas personas della, famosas y dignas de mucha e inmortal fama, pues enello se guarda la templança y moderacion que se deve, sin quitar a nadie lo suyo, como algunos tradutores hemos visto señaladamente Franceses, que los hechos y trabajos ajenos huelgan delos atribuyr y transferir a hombres de su nacion. (Ariosto 81)

En la traducción de Jiménez de Urrea las octavas "entremetidas" suman un total de 111 , mientras que las suprimidas eran $52 .{ }^{19}$ La mayor parte de ellas, más de 70, se introducen en el canto XXXV del poema (réplica hispánica al tex-

18. Para el detalle de estas octavas suprimidas ver el trabajo de Chevalier $(85$, n. 83).

19. Segre y Muñiz ofrecen relación de ellas en el estudio introductorio a su edición bilingüe (53). 
to original suprimido en el libro III, pues hace desfilar a "claros varones y mujeres de España: desde el Cid Campeador hasta los amigos y parientes del propio Urrea" (Segre/Muñiz 3027)..$^{20}$ Por su parte, Hernando de Alcocer también incluye sin dar aviso doce octavas nuevas a la gloria de los soberanos de España y de la casa de Austria en el canto XXVI, siete de ellas tras la octava 33 y cinco después de la 52 (Chevalier 85, n. 82). La labor de Gonzalo de Oliva, si hiciéramos caso de lo señalado por Clemencín, se creería la opuesta: una traducción estancia por estancia -esta vez sí- del texto de Ariosto. Lo cierto es que el lucentino cumple con este criterio en toda la traducción, salvo por una excepción que invalida la afirmación del erudito editor cervantino. En el canto XLIII elimina un total de 76 octavas, desde la 67 a la 143 , que incluyen la historia intercalada que un timonel narra a Rinaldo durante un viaje marítimo. Esta omisión le obliga además a modificar el texto del resumen de Dolce y el de la alegoría de Porcacchi para eliminar la mención a la historia suprimida. A continuación, traslado los textos italianos de la edición de Girolamo Polo de 1577, primera de las que pudo emplear Oliva, así como los de la traducción:

Due novelle Rinaldo in vitupero

De le Donne una, e l'altra intende ed ode

De gli huomini; e dapoi vario sentiero.

Reynaldo paladín parte por parte

Escucha de su [h] uesped el despecho

i aquella noche por el Pô se parte

Nella prima novella di questo Canto si mostra, quanta gran forza habbian ne' petti humani l'oro e le giogie: le quali spugnano tutti gli animi \& tutte le menti più falde, e insieme vengono avertiti i mariti a non curarsi di tentar quello nelle moglie, che trovato poi, recherebbe lor noia \& dispiacere. Nella seconda poi si nota, che di niun vitio è ripresa la Donna; del quale anco l'huomo non possa esser reo \& colpevole.

En la novela d'este canto se muestra, cuanta fuerza tienen en los pechos humanos el oro i las joyas, que vencen y derriban los ánimos y juicios más firmes. $\mathrm{Y}$ juntamente se advierte a los maridos, que no pretendan tentar

20. Como señala Micó, esa conducta "era bastante común y respondía al deseo interesado de traducir de manera efectiva el elemento panegírico que contenía el original” $(2006,11)$. 
en sus mujeres aquello, que hallado les puede causar enojo i desplaceres. En Orlando que con tanto onor entierra a Brandimarte, se nos pone delante el oficio de un verdadero amigo.

Como se advierte, mientras que Dolce y Porcacchi se refieren a las dos historias que le son relatadas a Rinaldo en el canto XLIII del texto ariostesco, Oliva solamente lo hace a la primera de ellas, pues ha decidido eliminar la segunda. Además, en la octava argumental se amplifica la mención a la primera historia para completar los versos y en la alegoría se añade la información del entierro de Brandimarte. Dejando a un lado esta excepcional intervención no he detectado ninguna otra supresión por parte de Oliva ni tampoco adiciones al poema. Traduce íntegro el encomio a la familia de Este del canto III, y respeta las controvertidas octavas de cuya eliminación había advertido Jiménez de Urrea en su Aviso.

En el libro XXXIV, en el pasaje que relata el viaje de Astolfo a la Luna en que el paladín se encuentra con san Juan, Jiménez de Urrea había llevado a cabo dos cambios sustanciales. En primer lugar, había omitido las octavas 58 y 59, que Oliva traduce sin reparos de la siguiente manera:

Juan el de Cristo sumamente amado, de quien aquella fama fue esparcida, que había de ser de muerte reservado y causa fue que el padre de la vida dijo a Pedro: ¿por qué te da cuidado, si así quiero que espere mi venida? No dijo ya que Juan no moriría, mas vese que decirlo así quería.

Entra Astolfo al palacio, y ve más gente, que el patriarca de la edad primera

Enoc y Elías profeta juntamente, que aún no han visto la noche postrimera, lejos deste aire inmundo y pestilente gozan allí perpetua primavera hasta que avise la celeste trompa que Cristo vuelve en majestad y pompa.

Y en segundo lugar, había reformado otra mención breve del evangelista en el último verso de la octava 61 que se refería a san Juan como "il discipul da Dio 
tanto diletto". Mientras que Jiménez de Urrea lo tradujo como: "el anciano venir a él derecho", Oliva lo tradujo así: "dicípulo de Cristo amado tanto", concretando aún más en Cristo el afecto por el joven apóstol. ${ }^{21}$

Tampoco suprime Oliva, como hiciera Jiménez de Urrea, tres octavas referidas al mal pago que reciben en vida los poetas por parte de los poderosos (XXXV 29), a la falta de caridad y al poder temporal de la Iglesia (XXXIV 80), ${ }^{22}$ y a la toma y pérdida de la fortaleza de Bastia frente a Alfonso I de Este, un episodio poco honroso de la historia militar española en Italia (XLII 5). Ni tampoco las duras críticas a unos religiosos que hace Ariosto en el canto XIV, octavas 81 y 82, las cuales había eliminado Jiménez de Urrea adelantándose al dictamen del índice de Sandoval, cuando el arcángel san Miguel acude a un monasterio por mandato divino en busca del Silencio y se encuentra en su lugar a la Discordia:

De Paz, Quietud, Piedad o de Amicicia

o de Humildad, señal ninguna mira.

Solían estar allí, mas de Cudicia

fueron echadas, de Soberbia y de Ira,

de Invidia, de Pereza y de Avaricia,

de Gula, de Crueldad; tal que se admira

el ángel, y mejor queriendo vellas

la Discordia halló también con ellas.

La que el eterno padre había mandado

fuese tras el Silencio de él buscada;

y al Averno bajar determinado

iba a buscarla en la región dañada

y agora (¿quién hubiera tal pensado?)

entre santos oficios fue hallada.

cosa estraña a Miguel le parecía

que en buscarla creyó haber gran vía.

21. También Alcocer, como señala en su carta a los lectores, modificó el pasaje sustituyendo la figura de san Juan Evangelista por la de "una santa guía, o un beato viejo, un amigo de Dios" (Gutiérrez Hermosa 118). No omitió la mención Vázquez de Contreras: "le dixo ser el que escribió el Evangelio, aquel tan amado del Redemptor, que fue traído aquí por divino querer, donde halló a Enoch y a Elías" (f. 174r).

22. Ariosto critica expresamente la Donación de Constantino, cuya falsedad documental había demostrado Lorenzo Valla fehacientemente en 1440, pero que seguía teniendo defensores. 
La censura inquisitorial no llegó al Orlando furioso en España hasta el Index librorum probibitorum et expurgatorum de Sandoval (1612), ${ }^{23}$ y el número y relevancia de los pasajes censurados fue mínimo. Se ordenaba expurgar exclusivamente cuatro porciones de texto que podían considerarse ataques contra las instituciones de la Iglesia y sus miembros: tres de ellas relativas a los pecados presentes en el mencionado monasterio -las cuatro octavas ya señaladas (XIV 79-82) y otros dos fragmentos más breves, de cuatro y seis versos cada uno (XVIII 26, 5-8 y XXVII 37, 1-6)-, y un verso que podría verse como un menosprecio a los santos de vida eremítica (XXXIV 30,4). Anteriormente, en el índice de Valdés (1559), no se condenaba ninguna obra de Ariosto, y en el de Quiroga (1583-1584) solamente se prohibió su sátira quinta. Si bien Oliva indica en el colofón a su traducción que se sometía al dictamen de la Inquisición (fig. 17), no suprimió nada del texto por iniciativa propia, a diferencia de Jiménez de Urrea o Alcocer. Todos los pasajes sobre los que después se dictaminó expurgo figuran fielmente en su traducción.

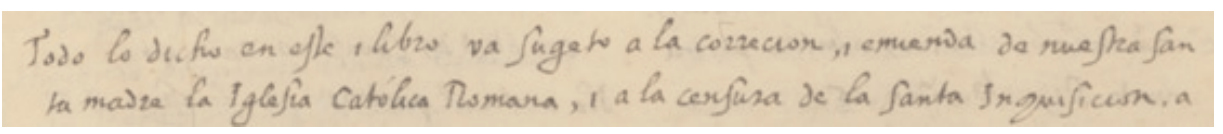

Figura 17. Colofón [selección] (f. 322r)

No obstante, al tiempo que apreciamos el distanciamiento de la traducción de Oliva de la de Jiménez de Urrea en estos pasajes, se debe señalar que también presenta intertextualidades evidentes con ella desde el comienzo mismo del poema. Por ejemplo, en la octava inicial del Orlando Oliva se sirve en su traducción de una de las rimas halladas por este (cortesía/Berbería):

\section{Ariosto}

Le donne, i cavallier, l'arme, gli amori, le cortesie, l'audaci imprese io canto, che furo al tempo che passaro i Mori d'Africa il mare, e in Francia nocquer tanto, seguendo l'ire e i giovenil furori d'Agramante lor re, che si diè vanto di vendicar la morte di Troiano sopra re Carlo imperator romano.

23. Sobre el proceso de inclusión del poema de Ariosto en el índice de Sandoval a partir de la delación de Luis de Torres Caro ver Bertini (1935). 


\section{Urrea}

Damas, armas, amor y empresas canto, caballeros, esfuerzo y cortesía, d'aquel tiempo que a Francia dañó tanto pasar moros el mar de Berbería, d'Agramante, su rey, siguiendo cuanto con juvenil furor les prometía en $\mathrm{el}^{24}$ vengar la muerte de Troyano sobre el rey Carlo, emperador romano.
Oliva

Damas, amor, belleza, i cortesía Caualleros, empresas, i armas canto; De quãdo el mar passó de Berbería, Dañino ${ }^{25}$ a Francia el Paganismo tãto, El juvenil furor, i valentía, De Agramante su rey siguiendo, i quanto Hazer juró en vengança de Troyano contra el rey Carlo Emperador Romano.

Como vemos, Oliva modifica la onomástica del original, mar de Africa, por la de mar de Berbería siguiendo a Jiménez de Urrea. Ahora bien, frente a él, coloca estas palabras cerrando los versos 1 y 3 con el fin de respetar la disposición del texto de Ariosto, y dejando la rima en -anto en la misma posición que en el original, la de los versos pares 2, 4 y 6 (fig. 18).

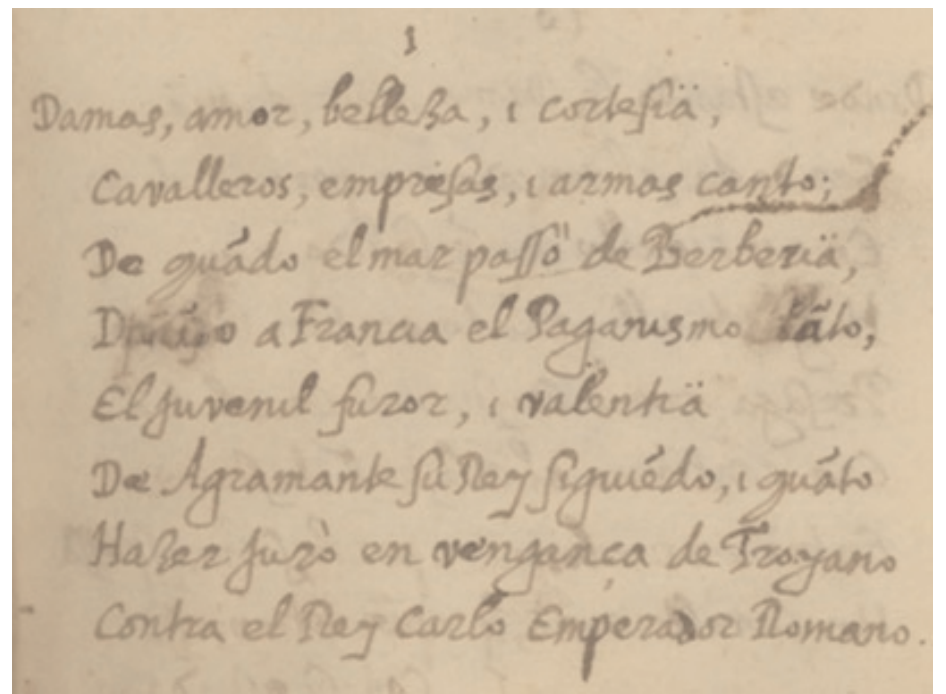

Figura 18. Orlando furioso traducido por Gonçalo de Oliva, I, 1 (f. 1r)

24. La edición de Segre y Muñiz presenta un error en el verso séptimo de la primera octava. En lugar de editar la palabra $\mathrm{el}$ como artículo, la edita como pronombre: "prometía, en él vengar"; con lo que la sintaxis resulta imposible. La confusión responde a que la preposición en no introduce un complemento del verbo vengar, sino un complemento circunstancial de prometer: "en el vengar..." = "a propósito de la venganza...".

25. Esta palabra ha sido reescrita en el manuscrito y su lectura no es clara. Parece que originalmente era dañoso y fue cambiada por dañino. 
Sobre la traducción de Jiménez de Urrea, se ha señalado que, siguiendo a comentaristas como Dolce y Fausto da Longiano, sometió al Orlando furioso a una adaptación programática con la intención de aproximarlo a la preceptiva (Chevalier 82-84), lo que dio como resultado un texto más próximo a la dignidad épica, púdico y respetuoso con la religión oficial; pero también menos ligero y risueño que el de Ariosto. La traducción de Oliva parece, en este aspecto, más cercana al texto original, pues, como ya hemos visto, no suprime pasaje alguno que pudiera considerarse satírico o burlesco, y es pretendidamente más fiel a la hora de trasladar contenido de este tipo. Presento a continuación algunos ejemplos en que la crítica había advertido una pérdida del lustre del original en la traducción de Jiménez de Urrea (Chevalier 79-80) y en los que, por el contrario, la de Oliva lo conserva:

OF, XXx 66, 5-6

Durindana tagliò cotenna et osso

e nel capo a Ruggiero entrò dua dita.

Urrea El yelmo, carne y hueso cortó el fiero; honda fue en la cabeza la herida

Oliva Entró por la cabeza la herida

Dos dedos cuero, carne i uesso abriendo.

OF, XXXII 76, 5-6

con tanta forza l'elmo gli percosse

l'asta che mai non fu abbasata invano.

Poi corse il re di Gotia, e ritrovosse

coi piedi in aria al suo destrier lontano.

Urrea con tal fuerça en el yelmo le ha herido que no abajó la lanza de oro en vano.

Corrió el de Gotia, y tal quedó tendido y su caballo dél no muy cercano.

Oliva [¡]Con tal fuerça prendió en el yelmo fino

L'asta de oro! i la dama buelta dando ${ }^{26}$

26. Adviértase de nuevo la intertextualidad de la traducción de Oliva con la de Jiménez de Urrea, pues l'asta de Ariosto pasa a ser una lanza de oro en la traducción del capitán y por influencia de esta se convierte en una asta de oro en la de Oliva. 
Al de Gotia encontró; q̃ le convino

De su caballo lexos ir bolando.

OF, XXXVI 20, 1-2

Forza è Marfisa ch'a quel colpo vada a provar se'l terreno è duro o molle.

Urrea Fuerza fue que Marfisa en tierra dura todos sus bellos miembros extendiese;

Oliva Marfisa del encuentro fue forçada de ir a vêr, si la tierra es blanda, o dura.

En el primero de estos ejemplos, vemos cómo Jiménez de Urrea disimula la imagen gruesa de la profundidad de la herida cifrada en dos dedos; en el segundo, cómo suprime la comicidad del caballero de Gotia volando por los aires; y en el tercero, cómo preserva la dignidad de la belicosa Marfisa evitando que la veamos evaluando la dureza del suelo. En cambio, Oliva conserva todos estos elementos, y con ellos el verdadero espíritu del poema. Otro ejemplo en esta línea nos permitirá introducir una última línea hermenéutica posible del manuscrito:

OF, XI 59, 1-2

che, quanto puè, nasconde il petto e'l ventre, più liberal dei fianchi e de le rene.

Urrea Cuanto ella puede, esconde pecho y vientre, de vergüenza muy pura y de gran pena.

Oliva Que cubrir pecho i vientre procurando, A descubrir la espalda i lado viene

En este fragmento referido a Olimpia, la dama oculta el pecho y el vientre en la medida que le es posible, pero deja ver el costado y la espalda -exactamente la zona de los riñones- ${ }^{27}$ En las traducciones españolas, frente a Jiménez de Urrea, que elimina toda nota de sensualidad insistiendo en el pudor de la dama, Oliva conserva su mayor liberalidad para mostrar ciertas partes del cuerpo. Pero además observamos en este caso una reescritura del traductor

27. El término renes se recoge en el Tesoro de Covarrubias y se refiere tanto a los propios riñones como a la zona en que se encuentran: "vale lo mesmo que los riñones, y aquella parte donde están". 
que había optado inicialmente por una adopción directa del término original rene, y que decide modificar por otro más usual, espalda (fig. 19).

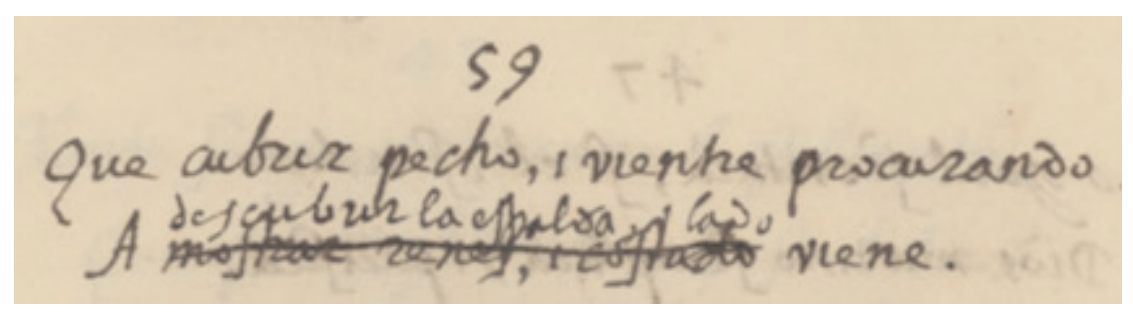

Figura 19. Orlando furioso traducido por Gonçalo de Oliva, XI 59, 1-2 (f. 63v)

Las correcciones de este tipo, como ya señalara Clemencín, son muy frecuentes en el manuscrito de Oliva. Pero su número e importancia disminuye a medida que avanza la obra, y de forma especialmente significativa a partir del canto vigesimoctavo, folio 191. Mientras que algunas de estas correcciones afectan exclusivamente a la forma final de un determinado verso, otras dan estructura nueva a octavas enteras e incluso a escenas que afectan a varias estrofas. Por señalar otro ejemplo atiéndase al caso de la octava 45 del libro XI, en que Oliva ha sustituido la rima en -endo (buyendo, sabiendo, horrendo), que empleaba desinencias verbales, por otra en -erta (Melicerta, acierta, muerta) (fig. 20). ${ }^{28}$

Además, debe tenerse en cuenta que la colación exhaustiva de las filigranas nos ha permitido observar que Oliva reemplazó seis folios a lo largo del manuscrito: 5, 35, 58, 64, 76 y 114 (respectivamente con las signaturas: A5, E3, H2, $\mathrm{H} 8, \mathrm{~K} 7$ y $\mathrm{P} 2)$; lo que, aunque no podamos precisar los motivos que le llevaron a hacerlo, supone el reemplazo de dieciséis octavas en cada caso. De este modo, el conjunto de correcciones llevadas a cabo por Oliva sobre su traducción, constituye un privilegiado caso de estudio para la filología de autor, que podrá ocuparse en apreciar el proceso de depuración literaria que se llevaba a cabo en el taller de los escritores áureos. ${ }^{29}$

28. El bajo estilo de las rimas empleando formas verbales lo señalaba por esa época Bernardo de Balbuena en su prólogo a El Bernardo: "porque [...] los consonantes en verbales humillan mucho el estilo y le descaecen, se ha huido todo lo posible" (vol. I, 78).

29. Sobre esta disciplina filológica ver Mazzocchi (2015) e Italia/Raboni; así como los restantes trabajos del monográfico Filología de autor y Crítica genética frente a frente comprendido en el segundo número de Creneida. Sobre la propia labor de reescritura de Ariosto en el Furioso, ver el trabajo clásico de Debenedetti. 


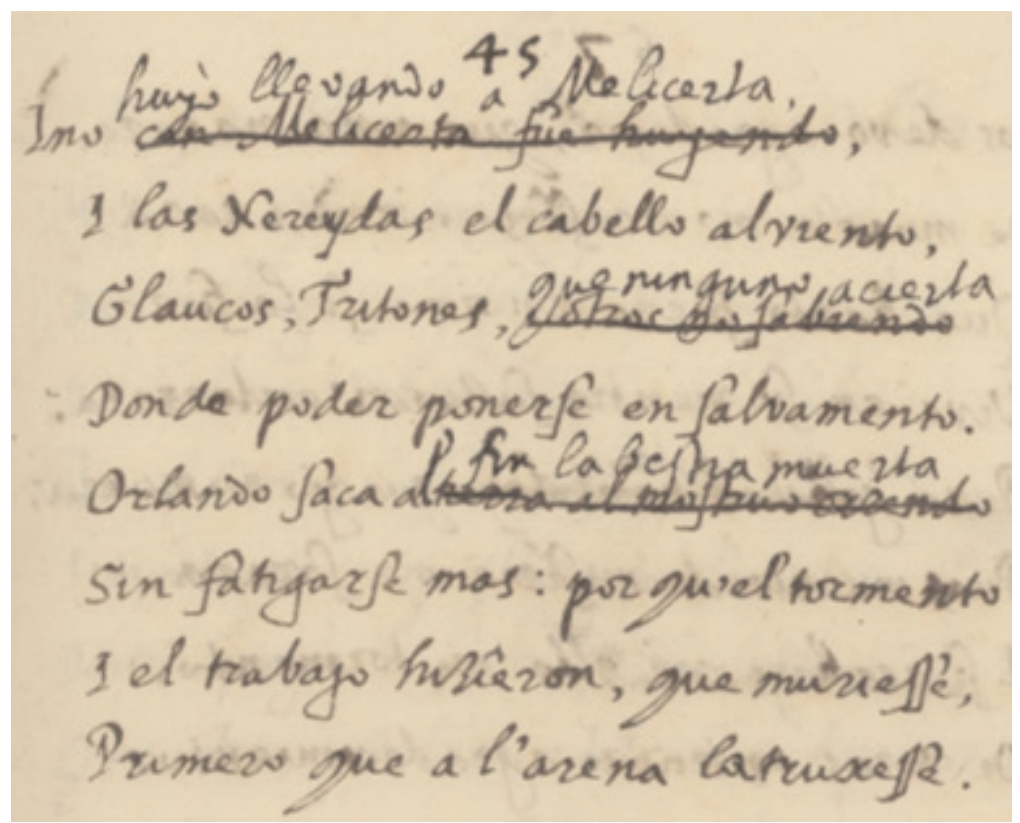

Figura 20. Orlando furioso traducido por Gonçalo de Oliva, XI 45 (f. 63r)

Concluye aquí nuestra somera presentación de este manuscrito poético. Solo resta una última pregunta, ¿qué interés puede tener hoy el hallazgo de este manuscrito, tanto para los estudiosos como para los lectores? En el estudio previo a su edición bilingüe del Orlando, Muñiz (35) hubo de plantearse algo similar a propósito de la publicación del texto de Jiménez de Urrea. En ese caso, solamente la amplia difusión en el Siglo de Oro justificaba que se editase. Y se unía a ello, en mi opinión, su no poco valor literario, aun con las conocidas omisiones, adiciones y modificaciones, y la diversa calidad de los versos. Sin embargo, se pronunció contra ello José María Micó poco después de publicar su aclamada traducción: "Todas esas traducciones en verso o en prosa, tienen un indudable interés histórico y filológico, pero no literario, y ni siquiera nos aseguran la comprensión literal y completa del texto de Ariosto" $(2006,11)$.

Si bien es cierto que las supresiones y adiciones suponen en la traducción de Urrea una falla para el acceso completo al texto del Orlando, no es cierto que pueda inferirse de ello que carezca de valor literario alguno; y el interés que pueda suscitar su condición histórica tampoco la menoscaba en aquel aspecto. $\mathrm{Y}$ es que tales cualidades no se sitúan, como parece presuponer Micó, en una oposición binaria. Dar por buena una afirmación tal, privaría de su va- 
lor literario, por ejemplo, a otras traducciones históricas como la siempre tenida por extraordinaria de Il Cortegiano que llevó a cabo Boscán. En particular, incide Micó sobre una cuestión en la que merece la pena que nos detengamos. Según él, traductores como Jiménez de Urrea o Juan de la Pezuela sufrieron lo que denomina la superstición de la forma, un prejuicio que consiste en primar la conservación de la forma estrófica, las octavas de Ariosto, aun cuando esto vaya muchas veces en perjuicio de la fidelidad al texto. ${ }^{30}$ Según Micó, "en el siglo XVI solo eran concebibles las dos soluciones extremas, o la octava con rimas $A B A B A B C C$, o la prosificación, pero hoy podemos buscar otras fórmulas que, evitando las tergiversaciones de las rimas forzadas, preserven la condición poética del original” $(2006,12)$.

Aun cuando es evidente que el hecho de conservar la métrica original es, a simple vista, un elemento de fidelidad y no de lo contrario, parece necesario insistir en que esta afirmación suya no es exacta. No lo es porque por aquella época no era la octava el único cauce poético de la épica. En el Siglo de Oro el endecasílabo blanco o suelto que Micó emplea fue el metro elegido por los traductores de los poemas épicos de la Antigüedad por el regusto clasicista que daba la ausencia de rima. Fue en este verso en el que vertieron sus traducciones Gonzalo Pérez (La Ulixea 1556), Juan Lebrija Cano (la Ilíada 1628) y, combinándolo con octavas reales, Gregorio Hernández de Velasco (la Eneida 1555). Y no solamente fue el vehículo de las traducciones de épica clásica, sino que se empleó también para la composición de algunos poemas nuevos como la Felicísima victoria de Corte Real (1578), la Historia de la Nueva México (1610) de Pérez de Villagrá o, el caso más elocuente de todos, El vitorioso Carlos Quinto (ca. 1571) del propio Jiménez de Urrea. De manera que el hecho de que este último, y también Alcocer y Oliva, tradujeran utilizando la octava y no las otras formas empleadas para la escritura épica (el endecasílabo blanco o los tercetos) no se debió a la ausencia de posibilidades, sino a una decisión voluntaria para tratar de ser fieles al texto. Y es que la octava, con su rima entrelazada de versos que se cierra en la rotundidad del pareado, es parte constitutiva de lo que es el Orlando furioso, y su ausencia ofrece un Orlando que lo es menos precisa-

30. También trae a colación varios ejemplos de traducciones palmariamente desacertadas de Urrea o de Juan de la Pezuela, en que el respeto de la rima influye en la desviación de la traducción literal. Ahora bien, la exigencia métrica no es el único elemento que influye en la fidelidad del traslado del texto, ni tan siquiera el más relevante, sino el talento de quien escribe; y podrían aportarse aquí casos en los que el propio Micó no es tan fiel como afirma, aun dentro de las condiciones métricas que se impone. 
mente por la forma, sí, pero sin superstición alguna. Como señaló Morreale: "L'ottava ariostesca constituisce un tutto autonomo, melodico, chiuso, lirico [...], que rappresenta nella sua complessa forma metrica un ideale di estrema difficoltà per traduttore che no voglia essere puro emulo" (35-36). Dificultad que con mayor o menor fortuna supieron afrontar Urrea, Alcocer u Oliva en función de su mayor o menor talento. $\mathrm{Y}$, sin pretender desmerecer su ímprobo esfuerzo y mérito, esto hubo de intuirlo el propio Micó, pues, aun prescindiendo de las rimas entrelazadas, decidió mantener los pareados al percibir la pérdida de carácter que supondría eliminarlos, y terminó empleando un remedo de octava. Así pues, ¿̇merece la pena estudiar y leer la traducción de Oliva? Considero que su traducción estancia por estancia -con la excepción en el canto XLIII-, su fidelidad a la forma, contenido y carácter del texto, su hacendosa labor de corrección, y al fin, el sabor genuino que le confiere su pertenencia a la misma época en que se escribió el texto original, así lo exige.

\section{OBRAS CITADAS}

Acuña, Hernando de. Varias poesías. Ed. Luis F. Díaz Larios. Madrid: Cátedra, 1982.

Agnelli, Giuseppe y Giuseppe Ravegnani. Annali delle edizione Ariostee con CXIV tavole fuori testo. 2 vols. Bologna: Nicola Zanichelli, 1933.

Ariosto, Ludovico. Orlando furioso. Ed. Cesare Segre y María de las Nieves Muñiz. 2 vols. Madrid: Cátedra, 2002.

Balbuena, Bernardo de. El Bernardo, o victoria de Roncesvalles. Ed. Martín Zulaica López. Pref. Alberto Montaner Frutos. 2 vols. Siero: Ars Poetica, 2017.

Bernstein Catalogue. <http://www.memoryofpaper.eu/BernsteinPortal/appl_ start.disp>.

Bertini, Giovanni Maria. "L'Orlando furioso nella sua prima traduzione ed imitazione spagnuola”. Aevum 8.2 (1934): 357-402.

Bertini, Giovanni Maria. "L’Orlando furioso e l'Inquisizione spagnola". Convivium 7 (1935): 540-50.

Bertini, Giovanni Maria. "Ludovico Ariosto e il mondo ispanico". Estudis Romànics 9 (1961): 269-82.

Cervantes, Miguel de. El ingenioso bidalgo don Quijote de la Mancha. Dir. Francisco Rico. Madrid: Real Academia Española, 2015.

Chevalier, Maxime. L'Arioste en Espagne (1530-1650): Recherches sur l'influence $d u$ "Roland furieux". Bordeaux: Institut d'Études Ibériques et Ibéro-américaines de l'Université de Bordeaux, 1966. 
Clavería, Carlos. "Le chevalier délibéré" de Olivier de la Marche y sus versiones españolas del siglo XVI. Zaragoza: Institución Fernando el Católico, 1950.

Clemencín, Diego, ed. Miguel de Cervantes. El ingenioso hidalgo don Quijote de la Mancha. 6 vols. Madrid: E. Aguado, 1833-1839.

Covarrubias y Orozco, Sebastián de. Tesoro de la lengua castellana o española. Eds. Ignacio Arellano y Rafael Zafra. Madrid: Iberoamericana, 2006.

Debenedetti, Santorre. I frammenti autografi dell'Orlando Furioso. Prem. Cesa-

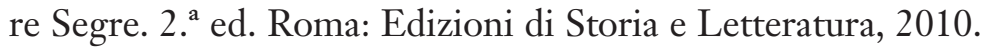

Díez Borque, José María. "Derechos de autor en los siglos de oro: antecedentes y consecuentes". Literatura, bibliotecas y derechos de autor en el Siglo de Oro (1600-1700). Dir. José María Díez Borque. Ed. Álvaro Bustos Táuler. Madrid: Iberoamericana/Frankfurt am Main: Vervuert, 2012. 193-244.

Gayoso Carreira, Gonzalo. Historia del papel en España. Lugo: Servicio de Publicaciones, Diputación Provincial de Lugo, 1994.

Geneste, Pierre. Le Capitaine poète aragonais Jerónimo de Urrea, sa vie et son oeuvre ou chevalerie et Renaissance dans l'Espagne du ХVI siècle. Paris: Ediciones Hispanoamericanas, 1978.

Gutiérrez Hermosa, Luisa María. "La Gerusalemme Liberata en España: T. Tasso y sus traductores en el Siglo de Oro". Tesis doctoral. Barcelona: Universidad Pompeu Fabra, 1999.

Italia, Paola y Giulia Raboni. “¿Qué es la Filología de autor?”. Creneida: Anuario de Literaturas Hispánicas 2 (2014): 7-56.

Jauralde Pou, Pablo, dir. Diccionario filológico de literatura española (siglo XVI). 2 vols. Barcelona: Castalia, 2012.

Juretschke, Hans. Vida, obra y pensamiento de Alberto Lista. Madrid: CSIC/Escuela de Historia Moderna, 1951.

López del Castillo, David. Memoria manuscrita del Siglo de Oro en la Biblioteca Nacional de España. Madrid: Calambur, 2013.

Mazzocchi, Giuseppe. "Dall'ottava dell'Ariosto all'ottava di Urrea: un traduttore e la metrica". La tela del Ariosto. El Furioso en España: traducción y recepción. Ed. Paolo Tanganelli. Anejo LXXI de Analecta Malacitana. Málaga: Universidad, 2009. 117-30.

Mazzochi, Giuseppe. "Filología de autor entre historia y método". Revista de la AIEMH (Asociación Internacional para el Estudio de Manuscritos Hispánicos) 1 (2015): 15-33.

Menéndez y Pelayo, Marcelino. Orígenes de la novela, I: Influencia oriental - Libros de caballerías. 1905-1915. Madrid: CSIC, 1943. 
Micó, José María. "Verso y traducción en el Siglo de Oro". Quaderns: revista de traducció 7 (2002): 83-93.

Micó, José María. "Filología y poesía en las traducciones de los clásicos: Ausiàs March y Ludovico Ariosto". Insula: revista de letras y ciencias bumanas 717 (2006): 10-12.

Micó, José María. "Las traducciones antiguas del Orlando furioso". El Trujamán: revista diaria de traducción. 4 de noviembre de 2010. <https://cvc.cervantes.es/trujaman/anteriores/noviembre_10/04112010.htm>.

Montaner Frutos, Alberto. Prontuario de bibliografía: pautas para la realización de descripciones, citas y repertorios. Gijón: Trea, 1999.

Morreale, Margherita. "Appunti per uno studio delle traduzioni spagnole dell'Orlando furioso nel Cinquecento". Le prime traduzioni dell'Ariosto (Atti del V Convegno sui problemi della traduzione letteraria). Padova: Antenore, 1977. 33-72.

Muñiz Muñiz, María de las Nieves. "Ariosto, Ludovico". Diccionario bistórico de la traducción en España. Coords. Francisco Lafarga y Luis Pegenaute. Madrid: Gredos, 2009. 59-62.

Muñiz Muñiz, María de las Nieves. "España e Italia: historia de una imagen refleja”. Ínsula: revista de letras y ciencias humanas 757-758 (2010): 33-37.

Parducci, Amos. "Note sulle traduzioni spagnole dell'Orlando furioso". Annali della Scuola Normale Superiore di Pisa, serie II 4.3/4 (1933): 243-54 y 313-25.

Pierce, Frank. La poesía épica del Siglo de Oro. Trad. J. C. Cayol de Bethencourt. Madrid: Gredos, 1968.

Pintacuda, Paolo. "El Orlando furioso traducido en prosa por Diego Vázquez de Contreras: notas de bibliografía textual". Le vie dell'epica ispanica, tra Ariosto e Tasso. Ed. Paolo Pintacuda. Lecce-Brescia: Pensa MultiMedia Editore, 2014.

Portnoy, Antonio. Ariosto y su influencia en la literatura española. Buenos Aires: Editorial Estrada, 1932.

Romera Castillo, José. "Hernando de Acuña: La Lira de Garcilaso contrahecha". Huir procuro el encarecimiento: la poesía de Hernando de Acuña. Eds. Gregorio Cabello Porras y Soledad Pérez-Abadín Barro. Santiago de Compostela: Universidade de Santiago de Compostela, 2011. 361-74.

Romero Blanco, Beatriz. Fosé del Castillo y Ayensa, bumanista y diplomático (1795-1861). Pamplona: Eunsa, 1977.

Segre, Cesare y María de las Nieves Muñiz, eds. Ludovico Ariosto. Orlando furioso. 2 vols. Madrid: Cátedra, 2002. 
Simón Díaz, José. Bibliografía de la literatura bispánica. 16 vols. Madrid: CSIC/Instituto Miguel de Cervantes de Filología Hispánica, 1983.

Van Horne, John. "The Urrea Translation of the Orlando Furioso". Todd Memorial Volumes Philological Studies. Vol. 2. Ed. John D. Fitz-Gerald y otros. New York: Columbia UP, 1930. 217-29.

Vaganay, Hugues. "Orlando furioso traduit par Urrea: les deux éditions lyonnaises 1550-1556". Revue Hispanique 81.2 (1933): 1-9.

Valls i Subirà, Oriol. Paper and Watermarks in Catalonia. 2 vols. Amsterdam: Paper Publications Society (Labarre Foundation), 1970.

Valls i Subirà, Oriol. The History of Paper in Spain. Madrid: Empresa Nacional de Celulosas, 1978.

Varo Zafra, Juan. "Diego Hurtado de Mendoza y las Cartas de los Bachilleres". Castilla: estudios de Literatura 1 (2010): 433-72.

Vian Herrero, Ana. Disfraces de Ariosto: Orlando Furioso en las narraciones de El Crotalón. Manchester: University of Manchester, Department of Spanish and Portuguese, 1998.

Wilkinson, Alexander S., ed. Iberian Books: Books Published in Spanish or Portuguese or on the Iberian Peninsula Before 1601. Leiden: Brill, 2010. 